\title{
Isotherm Sensor Calibration Program for Mars Science Laboratory Heat Shield Flight Data Analysis
}

\author{
Jose A. Santos* \\ Sierra Lobo, Inc, P.O. Box 344, Moffett Field, CA 94035, USA \\ Tomo Oishi ${ }^{\dagger}$ \\ Jacobs Technology, Moffett Field, CA 94035, USA \\ Ed R. Martinez $z^{\ddagger}$ \\ NASA Ames Research Center, Moffett Field, CA 94035, USA
}

\begin{abstract}
Seven instrumented sensor plugs were installed on the Mars Science Laboratory heat

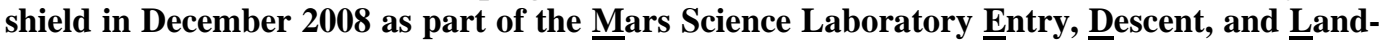
ing Instrumentation (MEDLI) project. These sensor plugs contain four in-depth thermocouples and one Hollow aErothermal Ablation and Temperature (HEAT) sensor. The HEAT sensor follows the time progression of a $\sim 700^{\circ} \mathrm{C}$ isotherm through the thickness of a thermal protection system (TPS) material. The data can be used to infer char depth and, when analyzed in conjunction with the thermocouple data, the thermal gradient through the TPS material can also be determined. However, the uncertainty on the isotherm value is not well defined. To address this uncertainty, a team at NASA Ames Research Center is carrying out a HEAT sensor calibration test program. The scope of this test program is described, and initial results from experiments conducted in the laboratory to study the isotherm temperature of the HEAT sensor are presented. Data from the laboratory tests indicate an isotherm temperature of $720^{\circ} \mathrm{C} \pm 60^{\circ} \mathrm{C}$. An overview of near term arc jet testing is also given, including preliminary data from $30.48 \mathrm{~cm} \times 30.48 \mathrm{~cm}$ PICA panels instrumented with two MEDLI sensor plugs and tested in the NASA Ames Panel Test Facility. Forward work includes analysis of the arc jet test data, including an evaluation of the isotherm value based on the instant in time when it reaches a thermocouple depth.
\end{abstract}

\section{Nomenclature}

Acronyms

MEDLI = MSL Entry, Descent, and Landing Instrumentation

MSL $\quad=$ Mars Science Laboratory

MISP $=$ MEDLI Instrumented Sensor Plug

CAD $=$ Computer Aided Design

HEAT $=$ Hollow aErothermal Ablation and Temperature Sensor

PICA $=$ Phenolic Impregnated Carbon Ablator

PTF $=$ Panel Test Facility

TGA $=$ Thermogravimetric analysis

TPS $=$ Thermal Protection System

\footnotetext{
* Mechanical Engineer, Thermophysics Facilities Branch, AIAA Member. Email: Jose.A.Santos@nasa.gov

${ }^{\dagger}$ Senior Engineer, ATOM contract, Thermophysics Facilities Branch, M/S 229-4

‡ Senior Research Engineer, Thermophysics Facilities Branch, M/S 229-4. AIAA Member.
} 


\section{Introduction}

$\mathrm{T}$ HE Mars Science Laboratory (MSL) heat shield was instrumented with seven sensor plugs as part of the Mars Science Laboratory Entry, Descent, and Landing Instrumentation (MEDLI) project. Each MEDLI Instrumented Sensor Plug (MISP) contains four in-depth thermocouples and one Hollow aErothermal Ablation and Temperature (HEAT) sensor. ${ }^{1}$ The basic construction of the HEAT sensor consists of two platinum-tungsten (Pt-W) wires, each electrically insulated, wound around a hollow Kapton tube; the hollow core is filled with a core piece of the same Thermal Protection System (TPS) material in which the sensor is installed. The completed HEAT sensor follows the time progression of an isotherm through the thickness of the TPS as the material is heated in a ground test facility or during atmospheric entry. The isotherm temperature which the HEAT sensor follows corresponds to the temperature at which the Kapton has sufficiently charred to establish an electrical connection between the two $\mathrm{Pt}-\mathrm{W}$ wires. The value of this isotherm temperature is based on thermogravimetric tests performed on Kapton samples, whose results were documented in the $1980 \mathrm{~s}^{2}$ However, the uncertainty of the isotherm temperature is not well-defined because it also depends on the material in which the HEAT sensor is installed. Thus, to characterize the isotherm temperature and its uncertainty specifically for the HEAT sensors installed in the phenolic impregnated carbon ablator (PICA) heat shield material of the MSL aeroshell, a calibration test program is being led and executed at NASA Ames Research Center. In addition to studying the isotherm temperature, the scope of the calibration program includes objectives designed to obtain data which will assist with the post-flight analysis of MISP data. In particular, determining a relationship between isotherm progression rate and TPS recession rate is a primary objective. The methods by which the flight data are used to estimate the aerothermal environment are described elsewhere. ${ }^{3}$ The MISP-HEAT calibration program consists of two components: laboratory experiments of HEAT sensor samples designed to investigate the isotherm temperature on a preliminary basis, and arc jet testing of flight-design MISP models.

\section{MISP-HEAT Calibration Program Overview}

\section{A. Test Objectives}

The objectives of the MISP-HEAT Calibration program are as follows:

1. Determine the isotherm temperature that the HEAT sensor follows and its corresponding uncertainty

2. Determine the accuracy of the isotherm depth determined from HEAT sensor data

3. Test the MISP flight design at conditions obtained from updated nominal and $-3 \sigma$ trajectories for MSL, both steady state and transient:

a. Which thermocouples burn out and under what conditions?

b. Is the HEAT isotherm temperature consistent with a thermocouple reading at the instant in time when the indicated isotherm depth reaches the thermocouple depth?

c. How accurately can char depth be determined from HEAT sensor data?

d. What is the relationship between isotherm progression rate and recession rate?

4. Evaluate whether MISP arc jet test results with air differ from those with $\mathrm{CO}_{2}$ as the test gas:

a. Is material/sensor performance in $\mathrm{CO}_{2}$ consistent with predictions?

5. Evaluate the accuracy of the analysis process proposed for flight data:

a. Are predicted aerothermal and TPS quantities within the MISP error budget?

Several test series are planned to investigate these topics, the first of which involves testing four, $30.48 \mathrm{~cm} \mathrm{x} 30.48$ $\mathrm{cm}$, flat panels in the 20 MW NASA Ames Panel Test Facility (PTF) at low heat flux conditions $\left(<50 \mathrm{~W} / \mathrm{cm}^{2}\right)$. Details of the model design and test conditions are provided in Section $V$ of this paper.

\section{Laboratory Experiments}

A series of laboratory experiments were performed to determine the isotherm temperature tracked by the HEAT sensor, along with its corresponding uncertainty. Thermogravimetric analysis tests and in-house furnace experiments of Kapton samples were the primary means of empirically estimating the isotherm temperature.

\section{A. Thermogravimetric Analysis Tests}

Thermogravimetric analysis (TGA) tests of Kapton tube and HEAT sensor constituent samples were performed at different ramp rates for various purge gas environments, including air, argon (Ar), helium (He), and carbon dioxide $\left(\mathrm{CO}_{2}\right)$. Figure 1 depicts the NETZSCH model STA 409 PC simultaneous thermal analyzer used to measure the mass change and transformation energetics of the test samples. The system is vacuum tight, a feature that enables mea- 
surements to be conducted under inert gas or oxidizing atmospheres. The TGA test data are used to plot a sample's change in mass as a function of temperature. Deviations in the mass are indicative of chemical reactions and can be readily seen on a plot of mass loss rate vs. temperature. When the sample no longer loses mass, the value is taken to be the char yield relative to the starting mass of the sample.

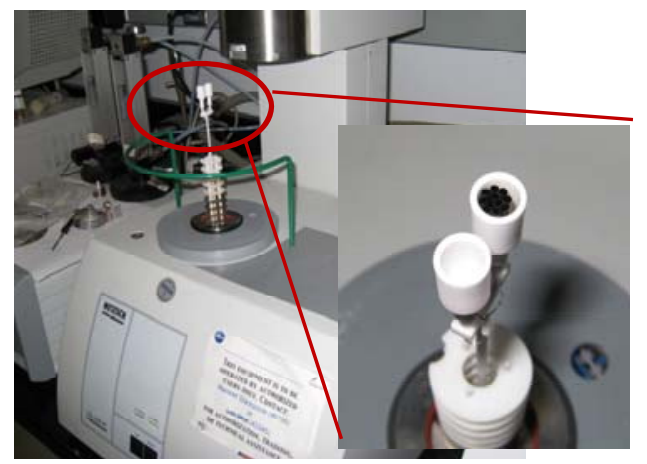

Figure 1. Thermogravimetric analyzer used to conduct TGA tests of HEAT sensor samples. A sample is placed inside the crucible and its mass loss is recorded as the crucible temperature is monitored.

\section{Test Conditions}

Table 1 summarizes the TGA tests performed for each type of sample. Cured liquid Kapton represents the coating of liquid Kapton applied to the HEAT sensor after the wires are wound around the Kapton tube. Figure 2 helps to illustrate the various constituent materials.

Table 1: Summary of TGA Test Conditions

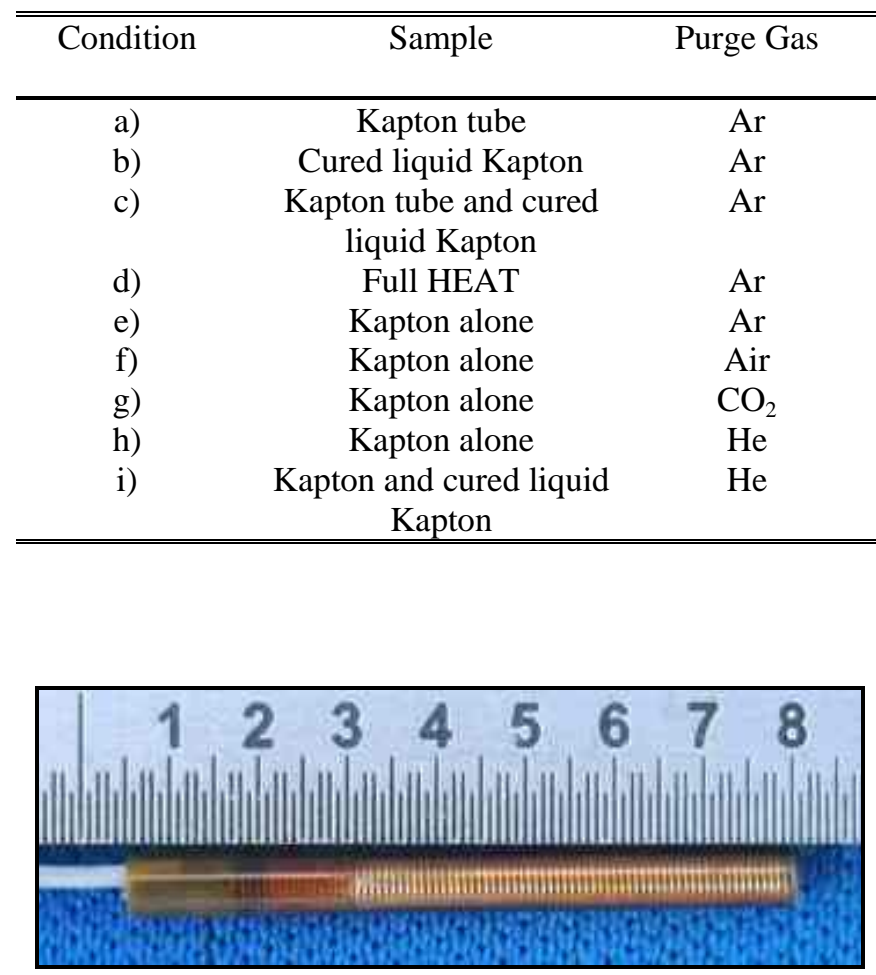

(a) Photo of HEAT sensor

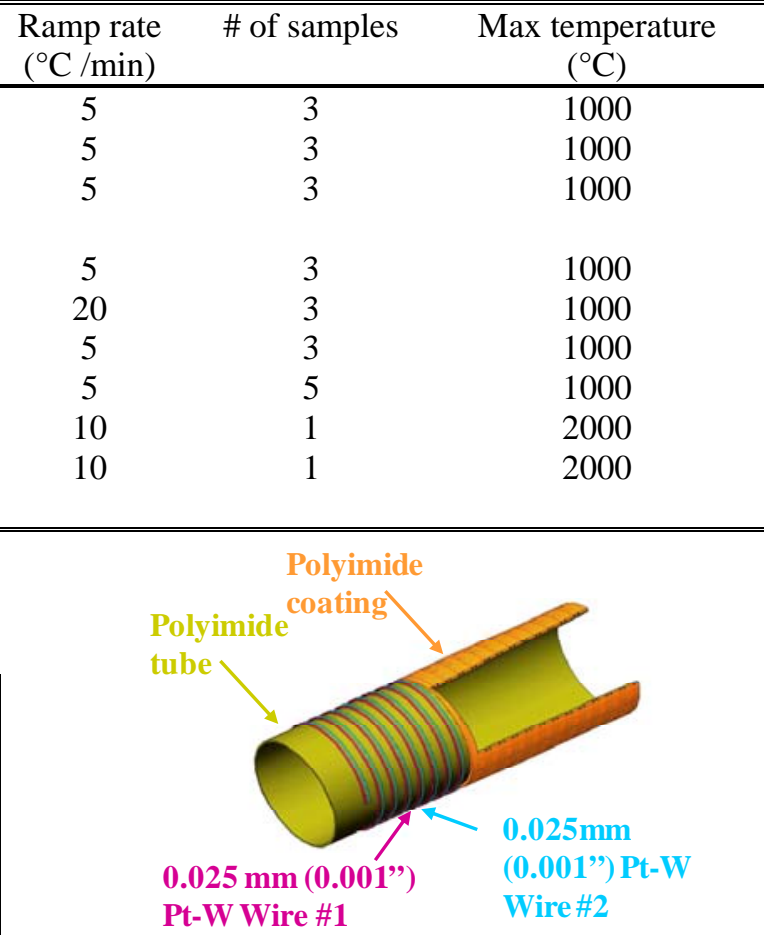

(b) Schematic of HEAT sensor construction.

Figure 2. HEAT sensor and its constituent materials. Two Pt-W wires are wound around the Kapton tube, and a liquid layer of polyimide coating is applied to further insulate the wires. An electrical connection is established when the tip of the sensor is heated, causing the Kapton to char and becomes electrically conductive. 


\section{2. $\quad$ Thermogravimetric Analysis Results}

For a given ramp rate and sample type, TGA results did not differ significantly when the purge gas was changed, except for the case of air in which the sample oxidizes and burns away completely. The results did differ, however, when different temperature ramp rates were used: a greater ramp rate "shifts" the TGA curve to the right suggesting that the onset of pyrolysis occurs at a higher temperature. This shift may be partly attributed to the fact that only the temperature of the crucible containing the test sample is monitored, not of the test sample itself. At higher ramp rates, the sample and crucible may not be in thermal equilibrium.

Figure 3a plots normalized mass vs. temperature for all of the TGA test runs (excluding the He runs). The test runs with Helium went up to $2000{ }^{\circ} \mathrm{C}$ and revealed a fully charred Kapton sample (effectively $100 \%$ decomposition) with $51.3 \%$ of its mass remaining. With this information, mass loss can be related to a fractional decomposed state. Furthermore, a simplified statistical-based analysis ${ }^{4}$ predicted that an electrical path to bridge the circuit between the two Pt-W wires forms at a decomposition state of approximately 58\%, which corresponds to $71.8 \%$ remaining mass in the Kapton TGA sample. Since the isotherm temperature corresponds to the value at which the Kapton chars just enough to establish an electrical signal between the two wires, a given TGA curve can be used to determine the isotherm value for different ramp rates. At $5{ }^{\circ} \mathrm{C} / \mathrm{min}$ with argon as the purge gas, the isotherm temperature was found to be $614 \pm 21^{\circ} \mathrm{C}$. It should be noted, however, that in targeted use the HEAT sensor will experience much higher temperature ramp rates when embedded in TPS materials that are exposed to convective heating environments.

Using ASTM standard E $1641-07^{5}$ as a guide, an Arrhenius plot was created as $\log$ (base 10) of temperature ramp rate vs. the reciprocal of the absolute temperature as shown in Figure 3b. A linear trend line is fit to the two available data points corresponding to the $5{ }^{\circ} \mathrm{C} / \mathrm{min}$ and $10{ }^{\circ} \mathrm{C} / \mathrm{min}$ ramp rates. Based on material response predictions and the total time taken by the MSL vehicle for atmospheric entry, lower and upper bounds on ramp rate were determined to be $140{ }^{\circ} \mathrm{C} / \mathrm{min}$ and $3720^{\circ} \mathrm{C} / \mathrm{min}$, respectively. Determining an isotherm temperature from these ramp rates requires extrapolation of the TGA data using the linear trend line shown in Figure 3. The isotherm temperature of Kapton is was found to be $721 \pm 60^{\circ} \mathrm{C}$ when expressed with a bilateral uncertainty. Arc jet testing planned under this calibration program will provide additional data points at higher ramp rates to evaluate the assumed linear dependence (on a logarithmic scale) of ramp rate with sample temperature.



(a) TGA test data for Kapton samples tested in various purge gas environments. The sample tested in air oxidizes and completely burns away (all of its mass is lost). The temperature at which Kapton becomes electrically conductive is at a TGA sample mass ratio of $71.8 \%$ based corresponding to a state of $58 \%$ decomposition.

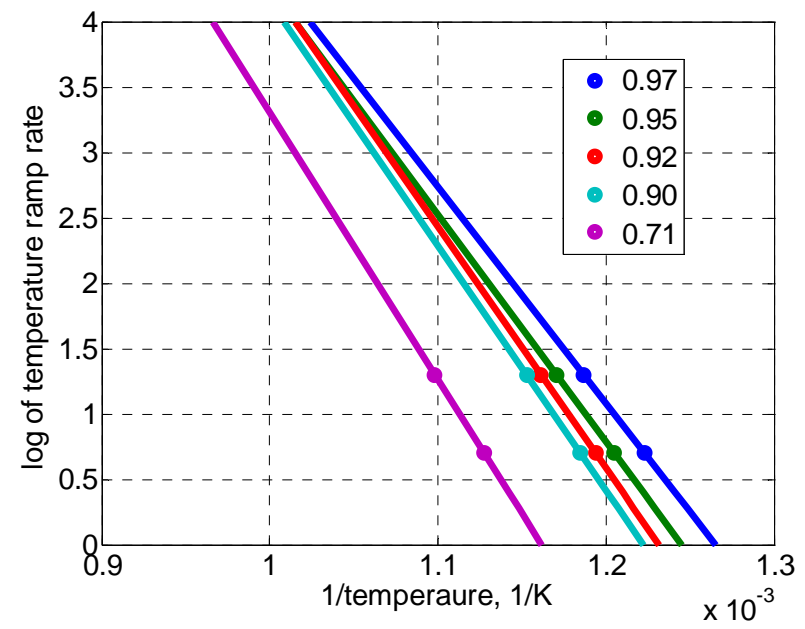

(b) Arrhenius plot of TGA test data: log of temperature ramp rate vs. inverse of temperature for the Kapton test samples. The two data points shown correspond to ramp rates of $5^{\circ} \mathrm{C} / \mathrm{min}$ and $10^{\circ} \mathrm{C} / \mathrm{min}$. Arc jet test planned for 2011-2012 will provide additional data points to evaluate the assumed linear dependence shown on the log scale.

Figure 3. TGA test data for Kapton samples. An Arrhenius plot is constructed to evaluate the dependence of the temperature at which Kapton chars and becomes electrically conductive with temperature ramp rate. A family of curves is obtained by using different normalized mass values (shown in the legend) as the threshold value

4

American Institute of Aeronautics and Astronautics 


\section{B. Furnace Tests}

\section{1. $\quad$ Test Setup \& Apparatus}

A custom-designed tube furnace was used to expose HEAT sensor samples to temperatures up to $750{ }^{\circ} \mathrm{C}$ in a laboratory setting. Resistance was recorded throughout each test sample's exposure to the furnace heating element. In addition, the test sample temperature was monitored with a thermocouple (although it was not located on the wire wound portion of the sensor but adjacent to it). Photos of the test setup are shown in Figure 4. A thermocouple inserted from the bottom and placed next to the sample was used to control the furnace temperature. A thermocouple was also placed on the outside of the argon-feeding alumina tube at the same vertical position as the thermocouple on the HEAT sample; this thermocouple was expected to read higher than the other two because it is on the outside of the alumina tube directly exposed to the furnace heating element. A cross-section of the tube furnace from a CAD model is shown in Figure 5.
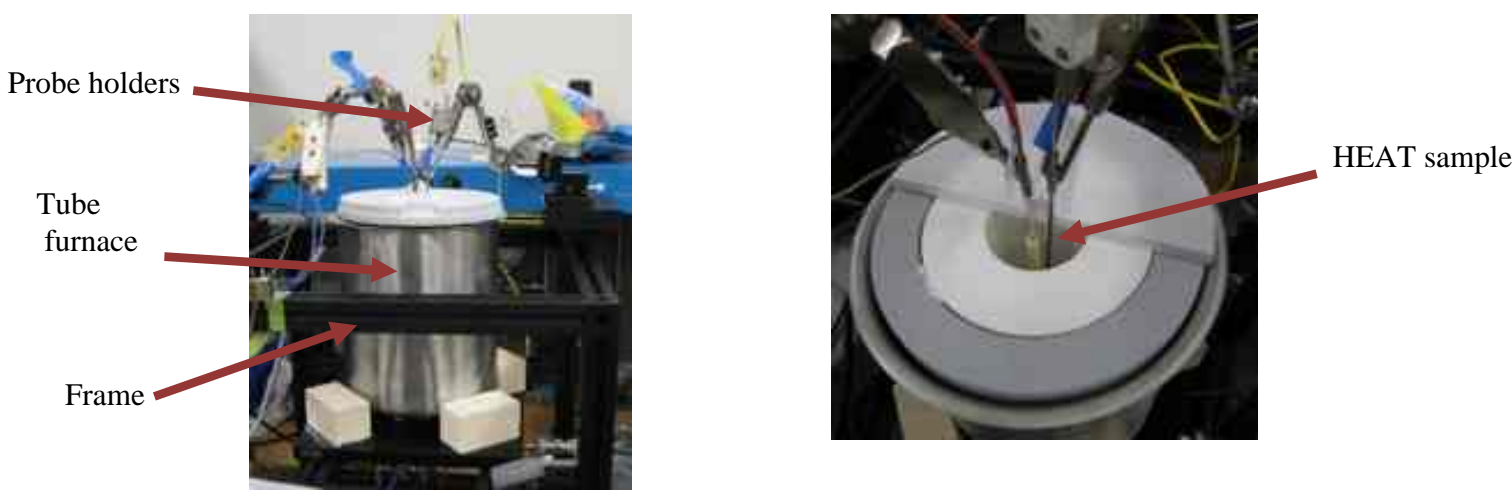

Figure 4: Photos of tube furnace test set up. The resistance of the HEAT sensor samples placed inside the furnace was monitored as the furnace temperature was varied from room temperature to $750{ }^{\circ} \mathrm{C}$.

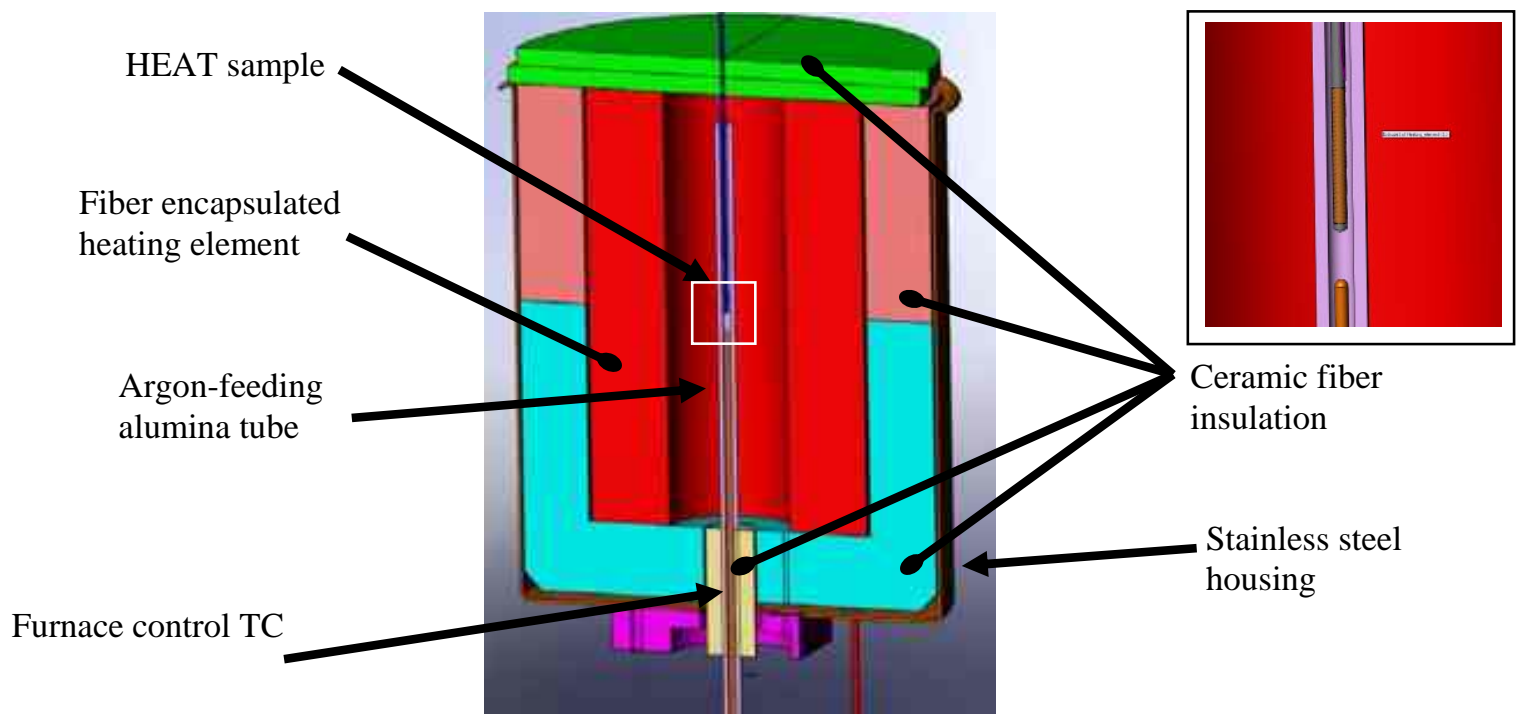

Figure 5. CAD model of tube furnace setup with gas "tight" alumina tube configuration, allowing argon to be fed inside the furnace as a purge gas to prevent oxidation.

The measured resistance of the HEAT sensor sample plotted against furnace temperature is given in Figure 6. The average slope of the initial upward linear trend was found to be $2.75 \mathrm{e}-4 \Omega / \Omega /{ }^{\circ} \mathrm{C}$ and represents the dependence of the Pt-W wire resistance reading with temperature. The slope may be used to correct the HEAT sensor output and determine a more accurate isotherm depth. The steep drop in resistance indicates the decomposition of the Kapton and the onset of an electrical connection between the wound Pt-W wires. Determining a single temperature value at 
which the latter occurs is not straightforward. One approach is to select a threshold normalized resistance value by examining when a deviation from the downward linear trend occurs. This value was estimated as 0.3 and corresponds to a temperature of $618{ }^{\circ} \mathrm{C} \pm 37^{\circ} \mathrm{C}$ after accounting for differences in the temperature readings between the three thermocouples described in the test set up. Note that this finding encompasses the $614{ }^{\circ} \mathrm{C} \pm 21^{\circ} \mathrm{C}$ result discovered in the TGA testing.

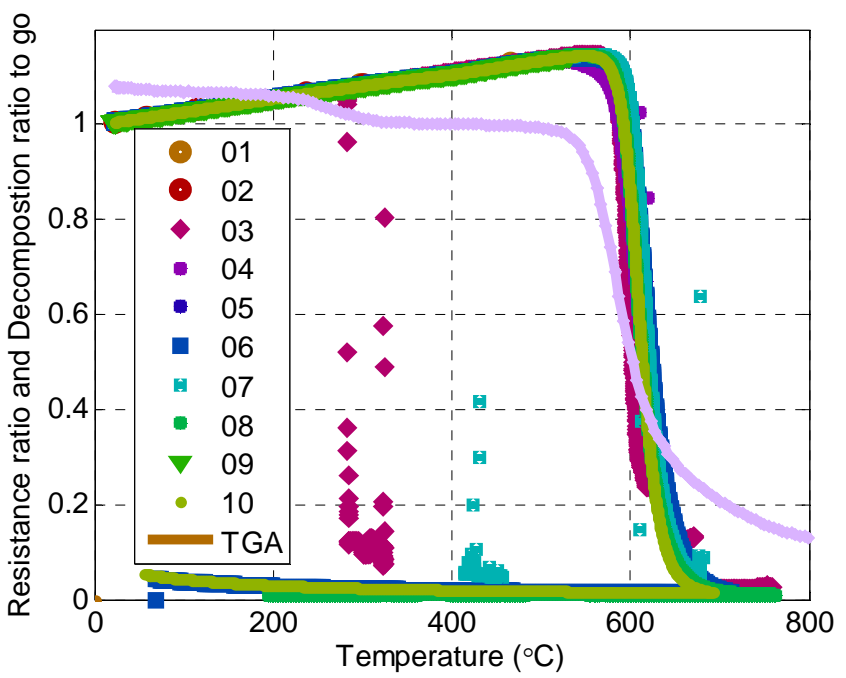

Figure 6: Normalized resistance of HEAT samples as function of temperature.

\section{Panel Test Facility Arc Jet Test}

\section{A. Test Objectives}

The PTF test runs are intended primarily to investigate the response of the sensors in the MEDLI Instrumented Sensor Plug (MISP) at low heat flux conditions, for both constant and transient conditions. The target heating rates were obtained from predicted $-3 \sigma$ environments for the flight MSL heat shield at the MISP locations. ${ }^{6}$ Past testing of MISP models has demonstrated to the MSL project that installation of the MISPs on the flight heat shield does not adversely affect the performance of the acreage thermal protection system material. However, these tests were conducted in higher heating regimes, based on the fully margined $+3 \sigma$ environments (max $q_{c w} \cong 220 \mathrm{~W} / \mathrm{cm}^{2}$ ). The proposed PTF tests are intended to measure and understand the MISP response at significantly lower conditions ranging from $15 \mathrm{~W} / \mathrm{cm}^{2}$ to approximately $50 \mathrm{~W} / \mathrm{cm}^{2}$.

\section{B. Model Design}

All test models are $30.48 \mathrm{~cm}$ square panels with two MISPs located $6.03 \mathrm{~cm}$ from the centerline axis of the model $(9.21 \mathrm{~cm}$ from the outer edge), and $9.22 \mathrm{~cm}$ from the leading edge, as seen in Figure $7 \mathrm{a}$. The MISP consists of a $3.30 \mathrm{~cm}$ diameter PICA plug with four bead-welded Type K thermocouples of $0.0305 \mathrm{~cm}$ diameter wire embedded at depths of $0.254,0.508,1.14$, and $1.78 \mathrm{~cm}$ relative to the outer mold line surface of the plug as manufactured. Each MISP also contains one HEAT sensor $(1.60 \mathrm{~cm}$ sensing length) located a radial distance of $0.823 \mathrm{~cm}$ from the center of the plug. The HEAT sensor location is taken as the 6 o'clock orientation of the plug. There are a total of four test models. Two of the four models have both MISPs bonded into the panel with RTV-560 (consistent with the flight installation method), while the other two have the West side MISP bonded with RTV-560 and the East side MISP press-fitted into the panel. Each model has two bond line thermocouples per MISP installation: one at the interface between the bottom of the plug and the PICA panel, and the second at the bond line between the PICA panel and insulator. 




(a) Top view of PICA panel (not to scale). Flow is from bottom to top.

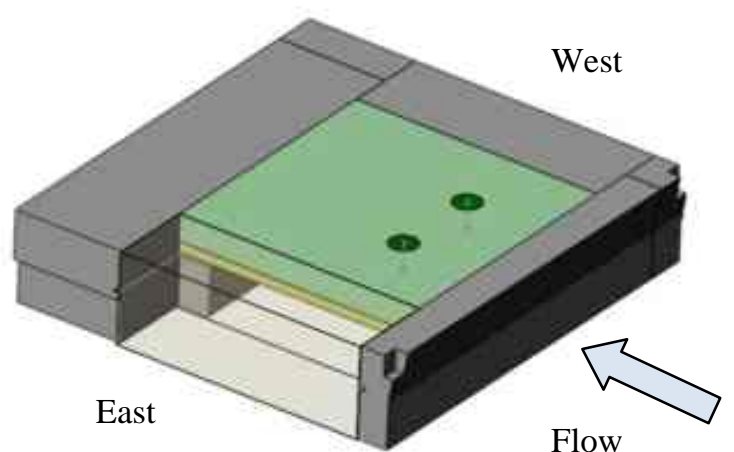

(b) CAD model of PICA test model assembly mounted in the PTF test box frame.

Figure 7. Test model design.

\section{Test Conditions}

The $-3 \sigma$ environments on which the test conditions have been based are provided in Table 2. Surface pressures achievable on the PTF test models will be significantly lower than MSL flight conditions - likely an order of magnitude smaller. However, for hot wall heating rates between 15 and $\sim 50 \mathrm{~W} / \mathrm{cm}^{2}$, the influence of pressure is expected to be minimal. In this regime, PICA will be acting primarily as a charring ablator with minimal recession. It must be noted that the configuration of the PTF is such that the test models experience flow from the initial start-up phase of the facility prior to reaching the test condition. Emphasis was placed on matching heat flux, and accepting the resulting surface pressure produced by the flow from the facility. Table 3 presents the target test conditions and run sequence. The ramp profile shown in Figure 8 attempts to simulate an increase in heating during the arc jet run-the thermocouple data will be examined to determine if the time at which the test condition transitions from 25 to 45 $\mathrm{W} / \mathrm{cm}^{2}$ can be detected.

Table 2: MISP -3 $\sigma$ Environments (09-TPS-01 Trajectory)

\begin{tabular}{ccccc}
\hline \hline $\begin{array}{c}\text { Flight MISP loca- } \\
\text { tion }\end{array}$ & $\begin{array}{c}\text { Peak } q_{h w} \\
\left(\mathrm{~W} / \mathrm{cm}^{2}\right)\end{array}$ & $\begin{array}{c}\text { Peak } p_{w} \\
(\mathrm{~atm})\end{array}$ & $\begin{array}{c}\text { Peak } Q_{h w} \\
\left(\mathrm{~J} / \mathrm{cm}^{2}\right)\end{array}$ & $\begin{array}{c}\text { Peak } \tau_{w} \\
(\mathrm{~Pa})\end{array}$ \\
\hline MISP T1 & 15 & 0.212 & 734 & 1.3 \\
MISP T2/T3 & 59 & 0.141 & 1990 & 221 \\
MISP T4 & 14 & 0.212 & 652 & 1.4 \\
MISP T5 & 25 & 0.144 & 1042 & 46 \\
MISP T6 & 49 & 0.136 & 1627 & 84 \\
MISP T7 & 13 & 0.123 & 502 & 15 \\
\hline \hline
\end{tabular}

Table 3: Target Test Conditions and Run Sequence

\begin{tabular}{ccccl}
\hline \hline Run \# & $\begin{array}{c}\text { Cold Wall } \\
\text { Heat Flux* } \\
\left(\mathrm{W} / \mathrm{cm}^{2}\right)\end{array}$ & $\begin{array}{c}\text { Exposure Time } \\
(\mathrm{sec})\end{array}$ & \# of Runs & \multicolumn{1}{c}{ Notes } \\
\hline 1 & 15 & 100 & 1 & Targets MISP T1 \\
2 & 45 & 54 & 1 & Targets MISP T6 \\
3 & (Ramp profile) & 80 & 1 & Attempt at trajectory simulation \\
4 & 30 & 50 & 1 & Targets MISP T5 \\
\hline \hline
\end{tabular}

*A factor of 1.2 is assumed to convert cold wall heat flux from a hot wall value in the absence of CFD data at these conditions. 


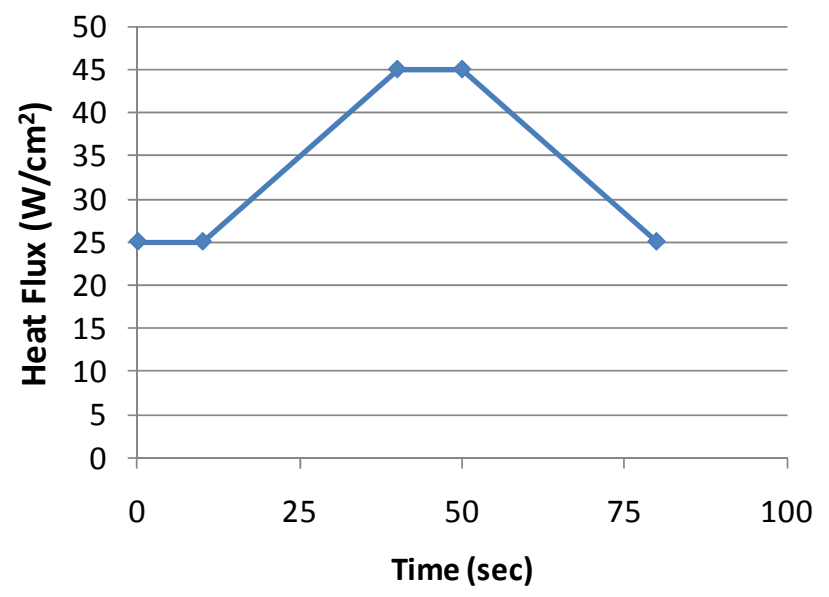

\begin{tabular}{c|c} 
Time (sec) & $\begin{array}{c}\text { Heat Flux } \\
\left(\mathrm{W} / \mathrm{cm}^{2}\right)\end{array}$ \\
\hline \hline 0 & 25 \\
10 & 25 \\
40 & 45 \\
50 & 45 \\
80 & 25
\end{tabular}

Figure 8. Ramp profile for Run 4

\section{Test Results}

A calibration plate containing twenty (20) Gardon gage heat flux sensors and twelve (12) pressure taps was used to calibrate the test conditions provided in Table 3. A schematic of the plate is shown in Figure 9, and the data for the ramp profile condition are plotted in Figure 10. The data show that the dwell times and transition steps are met within \pm 5 seconds while simultaneously maintaining the heat flux within $\pm 5 \mathrm{~W} / \mathrm{cm}^{2}$ of the target value, as evidenced by the data traces for gages 6-10 and 11-15. The West-side MISP (see Figure 7b) in the PTF panel model is located between gages 7 and 12 (although a bit closer to gage 7), while the East-side MISP lies between gages 9 and 14. A second run for this transient test condition was conducted to confirm the measurements and timing of the heat flux profile; although not shown, the data are also within the \pm 5 seconds and $\pm 5 \mathrm{~W} / \mathrm{cm}^{2}$, which verifies consistency in the operation of the PTF.

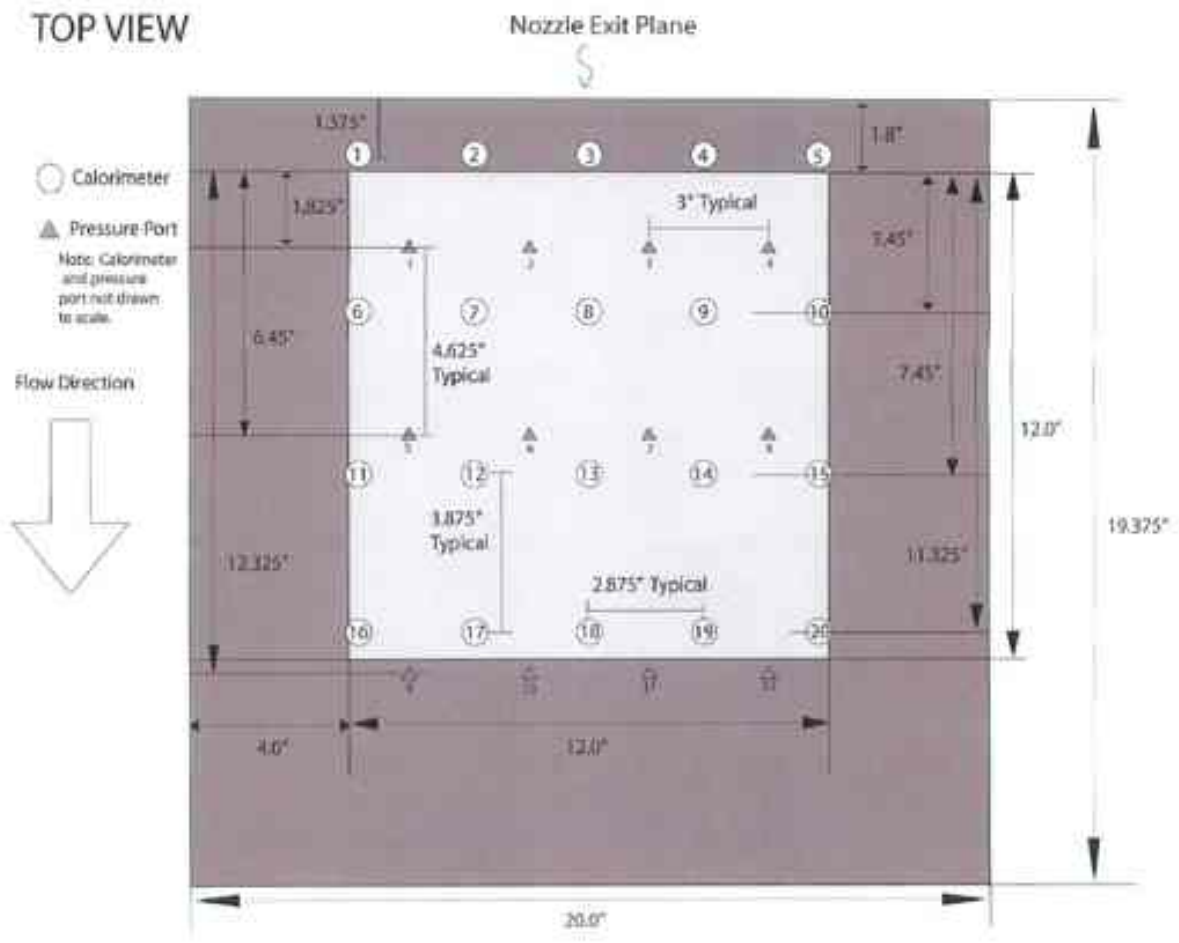

Figure 9. Schematic of calibration plate (courtesy of the NASA Ames Arc Jet Facility). 


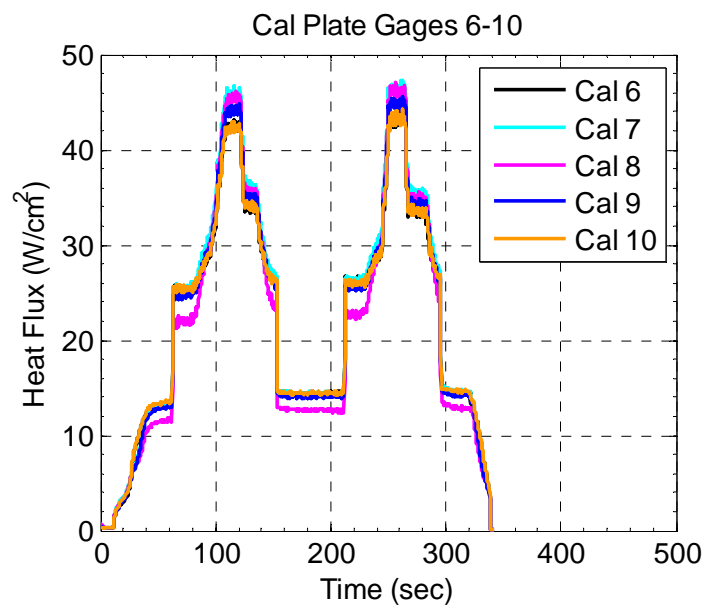

(a) PTF calibration data for gages 6-10 of the calibration plate.

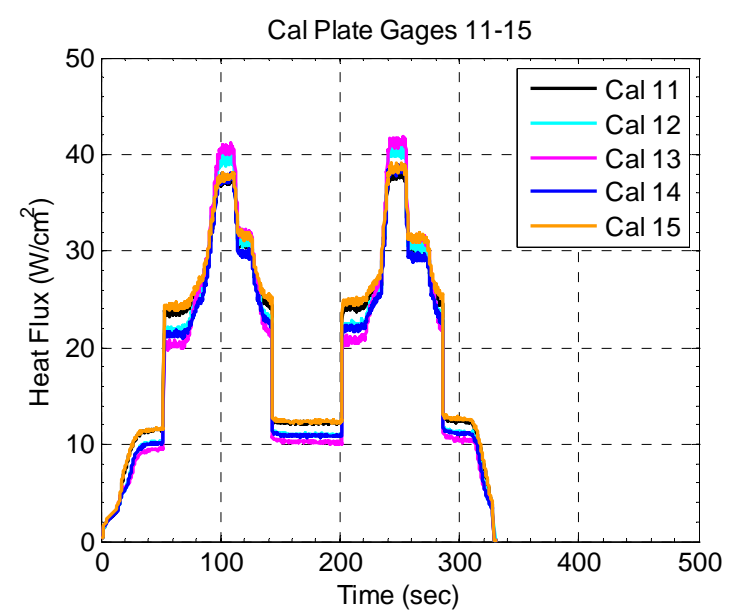

(b) PTF calibration data for gages 11-15 of the calibration plate.

Figure 10. Calibration plate data for condition 3 (ramp profile).

Two $30.48 \mathrm{~cm} \times 30.48 \mathrm{~cm}$ panel models have been tested in the PTF: one at condition 1 listed in Table 3 and another at condition 2. All thermocouples and HEAT sensors in both models responded to the arc jet flow environment. Thermocouple data for the East side MISPs are shown in Figure 11.

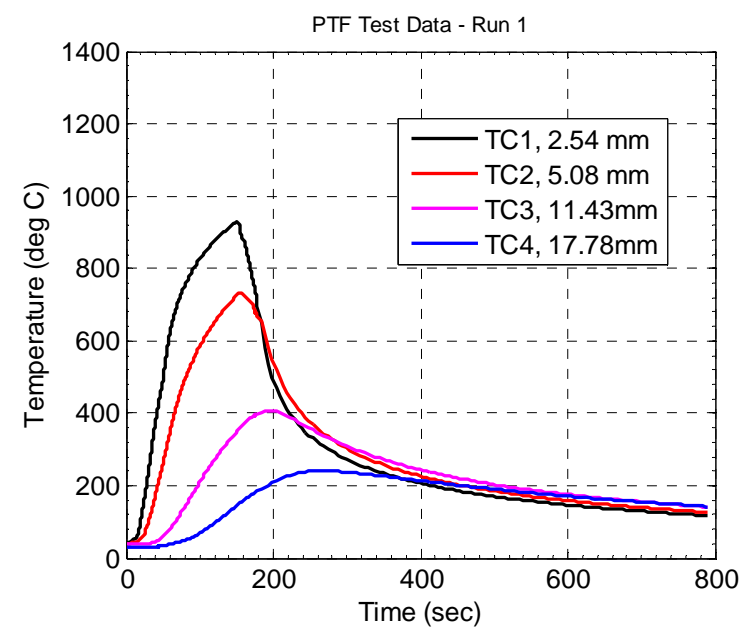

(a) TC data for East side MISP from Run 1.

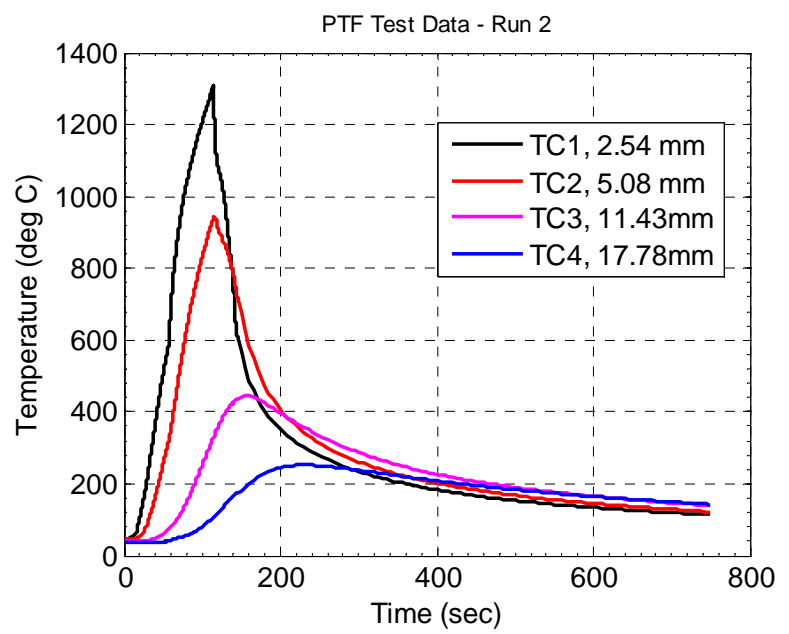

(b) TC data for East side MISP from Run 2.

Figure 11. Thermocouple data from the PTF arc jet test. Thermocouple depths from the surface of the model prior to testing are shown in the legend.

Peak temperatures for the top two near-surface thermocouples are noticeably lower at the lower heating condition as would be expected. The bottom two TCs are comparable since the total heat load of the $45 \mathrm{~W} / \mathrm{cm}^{2}$ condition was only 1.6 times greater than the total heat load for the $15 \mathrm{~W} / \mathrm{cm}^{2}$ setting. Analysis of the test data is ongoing. In particular, data from the HEAT sensors will be compared to the near-surface thermocouples to estimate the isotherm temperature at the instant in time when the isotherm depth reaches the depth of the thermocouple. The HEAT sensor data must first be corrected to account for the dependence of the wire resistance with temperature, as seen in Figure 6 . The results will then be evaluated to determine if the isotherm value obtained from each arc jet run falls within the $720 \pm 60^{\circ} \mathrm{C}$ window obtained by extrapolating the laboratory test results. 


\section{Conclusions}

The laboratory component of the MISP-HEAT calibration program has been completed, and the arc jet testing component has begun with tests of two $30.48 \mathrm{~cm} \times 30.48 \mathrm{~cm}$ panel models in the NASA Ames Panel Test Facility. There is good agreement between the results from the TGA tests and the laboratory furnace tests for the value of the isotherm temperature tracked by the HEAT sensor at the low ramp rates investigated. The laboratory tests also provided data to correct for the dependence of the HEAT sensor resistance with temperature, and showed that the isotherm temperature also has a strong dependence on temperature ramp rate. For ramp rates below $5^{\circ} \mathrm{C} / \mathrm{min}$, preliminary results from the laboratory experiments suggest the isotherm lies within $618^{\circ} \mathrm{C} \pm 37^{\circ} \mathrm{C}$. However, the HEAT sensors were exposed to much higher temperature ramp rates in the PTF model tests,

\section{Future Work}

Analysis of the PTF data is ongoing, and the next test series in the MISP-HEAT calibration program is planned for the fall of 2011 and will likely involve models in stagnation flow. Over 60 arc jet models will be tested over a oneand-a-half year period, prior to the expected landing date of the MSL rover in late summer 2012.

\section{Acknowledgments}

The authors would like to thank the NASA Exploration Systems Mission Directorate for funding the MEDLI project to carry out the MISP-HEAT calibration program. The authors would also like to acknowledge Mairead Stackpoole, Jeremy Thornton, and Jay Feldman from the Thermal Protection Materials Branch at NASA Ames Research Center for performing the thermogravimetric tests of the HEAT sensor samples. The NASA Strategic Capabilities Assets Program (SCAP) is also gratefully acknowledged for its critical financial support of the arc jet operational capability at Ames.

\section{References}

${ }^{1}$ Oishi, T., Martinez, E., and Santos, J., "Development and Application of a TPS Recession Sensor for Flight." AIAA Paper No. AIAA 2008-1219, January 2008.

${ }^{2}$ Cassanto, J.M., "A Simple Recession Gage for In Flight Measurement of the Char Degradation Zone for Reentry Vehicle Heat Shields," Instrument Society of America, $26^{\text {th }}$ International Instrumentation Symposium, Seattle, WA, May 1980.

${ }^{3}$ White, T., Cozmuta, I., and Santos, J., "Proposed Analysis Process for Mars Science Laboratory Heat Shield Sensor Plug Flight Data," AIAA paper to be presented at the $42^{\text {nd }}$ AIAA Thermophysics Conference in the Mars Entry Thermophysics Session, Honolulu, HI. June 2011.

${ }^{4}$ Oishi, T., and Santos, J., "Kapton Thermogravimetric Analysis for Hollow aErothermal Ablation and Temperature Sensor Calibration.” NASA Ames Research Center Sensor Development Lab internal memo, Sept. 2011.

5 "Standard Test Method for Decomposition Kinetics by Thermogravimetry," ASTM International, E 1641-07. 2007.

6 Edquist, K., et. al, “Mars Science Laboratory Entry Capsule Aerothermodynamics Environments,” Revision B, JPL Document D-34661-B, 8 Nov. 2008. 